\title{
POR UMA ÉTICA NA DEMISSÃO?
}

\author{
Maria Ester de Freitas \\ FGV-EAESP
}

0 mundo tremeu de indignação quando foram divul gadas as fotos de militares norte-americanos torturando e humilhando prisioneiros iraquianos na prisão de Abu-G hraib. A primeira pergunta que essa indignação suscita me parece ser: não é tudo permitido numa guerra?

Se a indignação demonstrada no repúdio explicitado por diferentes países é justa, isso significa que existem alguns compromissos morais que devem ser observados mesmo durante uma guerra. Não sou especialista em tratados de guerra e paz, tampouco nos meandros das convenções do Direito Internacional. Contudo, parece evidente que deve existir uma espécie de ética de guerra que preserve pelo menos alguns pontos, quais sejam: a) a guerra diz respeito aos Estados e não às pessoas; b) os soldados são diferentes dos civis, pois são armados e agem em nome dos Estados; c) as populações civis devem, na medida do possível, ser poupadas; d) os prisioneiros têm direito a manter preservada a sua integridade física e psicológica e a um julgamento justo; e) os vencedores têm obrigações humanitárias para com os vencidos sob o seu poder; f) os vencidos têm a obrigação de obedecer às condições acordadas com o vencedor.

Cada vez mais a comunidade internacional e as instituições de di- reitos humanos estão atentas à observância de princípios que reduzam a selvageria própria da guerra e abram a possibilidade de um pósguerra mais civilizado. Aqui, civilizado tem o sentido de oposto a bárbaro, a bruto, a ignóbil e a desumano. 0 que vale a pena reter é que uma guerra é apenas o ápice de uma seqüência de episódios resultantes de interesses contraditórios, que tiveram sua solução inviabilizada por meio da negociação e da barganha. Quer dizer, houve um esforço das partes antes de sua declaração, houve - pelo menos teoricamente - a possibilidade de resolução das diferenças e contendas antes do ataque. Mas ainda assim houve 0 aviso do ataque. Não se fazem mais guerras de surpresa, nem na calada da noite. Ainda que certos países façam guerra sem o apoio da comunidade internacional, cada vez mais parece que esse acordo tende a ser importante para legitimar a ação dos guerreiros.

Fizemos referência à guerra para ilustrar que, mesmo nas situações mais radicais e graves na vida de um país ou grupo, al gumas condições de respeito humano ainda são mantidas, e, quando são violadas, despertam a repulsa e a reprovação dos demais. $E$ o que tem isso a ver com o mundo das organizações modernas, como as empresas privadas e outras instituições, como as escolas, as universi- dades, os hospitais e órgãos da administração pública?

Para responder a essa pergunta, precisamos dar uma olhada rápida para as reengenharias ocorridas na década de 1990. É certo que o movimento de revalorização das empresas as colocou como o modelo de gestão por excelência que deve ser seguido por outros formatos organizacionais, ainda que as suas finalidades não guardem semel hanças. $\mathrm{Ou}$ seja, vale a lógica em que o critério baseado em custos dê sempre a palavra final ao processo decisório, que subordina os demais pontos a serem julgados, tal como os benefícios envolvidos nos compromissos assumidos e discursados em al to tom.

$N$ a década de 1990, especialmente no Brasil, onde o peso da maioria dos sindicatos é insignificante e cujo capitalismo é obcecado pela queima de etapas, os processos de reengenharia das empresas, salvo raras exceções, foram marcados pelo excesso de equívocos. Equívocos que, como tive a oportunidade de discutir em outro momento, ${ }^{1}$ dizem respeito à forma simplificada, mal definida e mal operacionalizada dessas reestruturações. Simplificada porque foram centradas em meros cortes de custos; mal definida porque se confundiu realinhamento estratégico com curto prazo; e mal operacionalizada porque se comete- 
ram vários desatinos, desrespeitos e demonstrações explícitas de insensibilidade, crueldade, cinismo e irresponsabilidade no trato com os profissionais que foram demitidos.

0 artigo acima referido é intitulado "O day-after das reestruturações", e causou certo frisson nos leitores dessa revista, pois recebi diversas cartas compartilhando o ponto de vista ali defendido e brindando-me com mais exemplos da pusilanimidade e da covardia com que algumas empresas estavam agindo na hora das demissões. A penas para relembrar um pequeno trecho,

[...] muitas demissões foram feitas por e-mail, por telefone, no meio das férias, no final do expediente quando o indivíduo já estava no estacionamento e por atos covardes semelhantes. Muitas coisas foram empacotadas e enviadas por boys para se evitar o constrangimento causado por uma presença infeliz. Negou-se ao homem demitido não apenas o direito de limpar as suas gavetas ou armários, mas também 0 de demonstrar a sua humanidade, fosse no adeus aos colegas de tantos anos, fosse na face que exprimia uma dor. Em boa medida uma dor que não estava relacionada simplesmente com a perda do emprego, mas por ser tratado como um lixo, como um nada, como um ninguém. ${ }^{2}$

Ora, não se questiona aqui o fato de as organizações demitirem. Demissões, assim como admissões, são fatos corriqueiros da vida organizacional. É bem verdade que houve uma mudança na natureza dos processos, pois antes as demissões eram no singular e agora são no plural, como já analisou Miguel Caldas. ${ }^{3}$ É senso comum que hoje o mundo dos empregos passa por uma grande re- visão, que as carreiras longas acabaram, que novas qualificações são requeridas, que a competição está mais acirrada, que as organizações devem apresentar resultados máximos em prazos menores; enfim, que a reengenharia se transformou numa prática constante. Não é difícil compreender isso. Estamos tratando aqui da aprendizagem que 0 modelo de demissões citado acima gerou, pois várias empresas que assumiram aquela postura tiveram muito do que se arrepender, fizeram mea-culpa e tiveram sérios arranhões não só internamente quanto junto ao público exterior. Muitas pagaram um preço enorme pelos desmandos cometidos e algumas continuam pagando, pois fazem vista grossa para o que a experiência já validou como um caminho a ser evitado. U ma parte desse preço diz respeito ao fomento a um comportamento cínico e mercenário que se desenvolveu no seio de várias organizações.

Em países desenvolvidos, ainda que as demissões não sejam uma ocorrência rara, costumam ser discutidas e negociadas com representantes de categorias e sindicatos. Geralmente são vistas outras possibilidades, como remanejamentos, requalificação, incentivos às demissões voluntárias ou antecipação de aposentadorias para os profissionais com muitos anos de serviço. Mas no Brasil não é bem isso que acontece, seja porque os sindicatos real mente são mais frágeis, seja porque o poder de as empresas legislarem internamente é muito maior e os excessos são raramente castigados. De qualquer forma, é inconcebível ocorrerem demissões de surpresa e sem discussão com os afetados e seus representantes. De novo repito: não estou analisando as razões pelas quais as demissões possam ser feitas, mas as maneiras como elas têm ocorrido e as ofensas ao ser humano em sua dignidade.

Pretendo levantar alguns pontos que podem talvez contribuir para 0 desenvolvimento de um comportamento organizacional mais responsável, menos danoso para as pessoas e também para as organizações. Sim, porque é preciso ter claro que as organizações não têm preocupações outras além do seu próprio bem-estar. A té esse ponto não há problema al gum: é de sua natureza artificial e expansionista racionalizar práticas e instrumentalizar variáveis para atingir os seus objetivos. Concessões, negociações e barganhas são apenas meios para se concretizarem resultados; a linguagem que as organizações falam é a dos interesses, começando pelos seus, e eventualmente pela convergência de interesses alheios que possam ser capitalizados. Não existe nada de errado nisso, é a sua lógica.

Como já afirmava Guerreiro Ramos, não se pode culpar o leão por ser carnívoro. Não se pode esperar aquilo que a natureza da coisa nega. É preciso ter em mente que as organizações são por natureza animais carnívoros, que se al imentam diariamente das disputas com a concorrência e das forças que são capazes de gerar internamente. 0 gozo que importa é o seu, e se para isso precisarem lançar mão de al gumas amabilidades, elas o farão sem pudor. Portanto, a única forma de se conseguir um comportamento organizacional respeitoso é demonstrar que o respeito não precisa ser exercido por mérito nem por qualidades morais. Mas porque 0 desrespeito atenta contra os seus objetivos, afasta o comprometimento necessário das forças internas, gera desmotivação e ressentimentos, desconstrói a firmeza de propósitos, desobriga o 
outro de cumprir a sua parte. É mostrar também que, é óbvio, se todos numa empresa esperam ser traídos ou tratados com desprezo, não existe razão para se crer no tecido organizacional como uma maIha protetora que merece cuidado e dedicação. Será a corrida de quem trai primeiro.

André Comte-Sponville pode nos esclarecer al guns pontos quando afirma a necessidade de distinguir as ordens econômico-tecnocientífica, jurídico-política, moral e ética. ${ }^{4}$ Ele assume que o retorno da discussão moral está na moda, apesar de não ser uma moda. Durante a guerra fria, 0 capitalismo podia se sentir justificado do ponto de vista moral por sua oposição ao comunismo. Agora ele precisa encontrar outras justificativas, pois vive sem adversários e representa um quase-monopólio ideológico. Mas as sociedades têm horror ao vazio, e por isso precisam encontrar justificativas. Assim, a atual discussão moral vem preencher essa lacuna. No entanto, a questão moral é mais o discurso do que o comportamento das empresas, pois é uma ética que melhora o clima interno, melhora a imagem, melhora o desempenho, ou seja, uma ética que faz vender. 0 autor se diz altamente perplexo, pois, como filósofo, é primeira vez que vê uma virtude ser fonte de lucro, uma virtude que faz ganhar dinheiro. Isso não significa que não se possa ganhar dinheiro honestamente ou que 0 dever e 0 interesse não possam coincidir em determinadas situações. Porém, se uma escolha é feita por dever ou por interesse, tem sentidos diferentes, pois o valor moral consiste fundamental mente numa escoI ha desinteressada. Para ilustrar essa afirmação, Kant nos dá como exemplo o caso do comerciante que é honesto para manter os seus clien- tes. Ele sabe que, ao primeiro deslize, perderá clientes e, portanto, perderá mais dinheiro do que poderia obter com tal deslize. Ora, então é melhor ser honesto, mas essa honestidade é exercida pelo interesse e não pelo dever de ser honesto. Se a ética na empresa é uma fonte de lucro ou uma forma de evitar perdas, ela é do signo da gestão e do marketing, e não da moral ou da ética; ela é diluível e instrumental.

Voltemos à distinção das ordens citadas acima. A ordem tecnocientífica tem a ver com o campo de pertinência dos problemas e das questões, bem como os limites dentro dos quais um dado saber é capaz de dar resposta. 0 autor participou de um colóquio em que vários economistas discutiam o preço do cacau e um deles disse: "Já fazer algum tempo que o preço do cacau está além do que a decência pode tolerar". A sua resposta foi: "Entendo o que o senhor quer dizer e concordo com isso, mas a decência não é uma noção econômica". Ora, a economia tem competência para dar outras respostas, não, porém, para definir o que é decência, por exemplo. Essa ordem é da definição do possível e do impossível, do viável e do inviável, do passível de execução ou não com os recursos de que se dispõe. A tendência é o saber caminhar do possível ao impossível, e ela não tem como se limitar internamente. Portanto, é necessário que o controle venha do exterior.

A ordem jurídico-política trata concretamente da lei e do Estado, discorre sobre a oposição entre 0 legal e o ilegal, e de quem o autoriza. Mas a lei, por exemplo, não proíbe a mentira, nem o egoísmo, nem o desprezo, nem o ódio. Ora, mesmo que se tenha claro o que é legal e quem aplica a lei, tanto do ponto de vista individual como do coleti- vo, ninguém está isento do espectro do legalista maldoso, ou seja, de alguém que, mesmo respeitando a lei, possa cometer grandes desatinos. Essa ordem também é incapaz de controlar a si própria, e, assim, é necessário que o controle venha do exterior.

A ordem moral diz respeito à verdade, à liberdade, ao humanismo, à honestidade, ao dever. Existem coisas que a lei autoriza, mas que devemos nos proibir; outras que a lei não nos impõe, mas que cabe a nós nos impor. A consciência de um homem honesto é mais exigente que o legislador, e o indivíduo têm mais deveres que o cidadão. Se uma lei racista, por exemplo, não contraria a Constituição de um país, ainda assim, do ponto de vista moral, ela é indefensável. Essa ordem é internamente estruturada pela oposição do bem e do mal, do dever e da proibição. Ela se impõe por si mesma, independentemente de sanção ou de recompensas externas. É o conjunto que se impõe incondicionalmente por uma dada consciência, mas existe o risco do moralismo. A diferença está em que a moral se ocupa do dever e o moralismo, do dever dos outros. Dessa forma, é preciso que essa ordem seja complementada pela ética, que é usada quase que alternadamente com a moral.

A ordem ética pertence à ordem do amor. Para o autor, a distinção é simples: moral é o que se faz pelo dever; ética é o que se faz pelo amor, e é estruturada pel a oposição da al egria à tristeza. Ela compreende 0 amor à verdade, à honestidade, à humanidade ou ao próximo. É o amor que pode intervir nas ordens precedentes sem as abolir, como, por exemplo, o amor à verdade, ao trabalho bem-feito e à justiça.

Comte-Sponville afirma ainda que as ciências não têm moral, tam- 
pouco as técnicas. Em lógica não existe moral: na matemática, 2 mais 2 é sempre igual a 4, e não cabe se isso é ou não moral. 0 mesmo raciocínio vale para as demais ciências quanto à sua essência: mesmo em economia, quando se maximiza o bem-estar como comportamento racional, não se trata de uma abordagem moral, pois se trata de interesse e não de dever, ainda que o racional nem sempre seja razoável nem virtuoso. Por exemplo, um assassino pode ter um comportamento perfeitamente racional, e não será menos culpado por isso. 0 que 0 autor ressalta é que a ordem econômicotecnocientífica não é jamais moral, nem imoral. Isso não impede que fatores psicológicos e sociológicos intervenham na economia, como a necessidade de confiança do mercado, por exemplo, mas essa confiança é uma evidência econômica e não moral: o mercado pune quem o trai. $\mathrm{N}$ ão é a moral que determina os preços, é a oferta e a procura; não é a virtude que cria o valor, é o trabaIho; não é o dever que comanda a economia, é o mercado. ComteSponville é categórico: o capitalismo não é moral nem imoral, é apenas amoral. Se quisermos moral na sociedade capitalista, ela não poderá vir da economia, não podemos contar com o mercado para ser moral em nosso lugar.

Voltemos às demissões. Não podemos pedir às empresas ou organizações que não demitam porque isso não é moral. Elas têm objetivos para atingir, e as demissões podem ser os meios de atingir esses objetivos, sendo, portanto, contra a sua natureza recusar as saídas que lhes permitam atingir o alvo. Também não é ilegal demitir alguém, desde que se cumpra o estabel ecido em lei, seja com relação a prazos ou a direitos. Quando alguém é admitido numa empresa, bem sabe que o foi porque existia o interesse profissional, e por isso não deve nenhuma gratidão ao seu chefe. Da mesma forma, quando alguém aceita um emprego, faz isso por interesse, e o chefe não Ihe deve nenhuma gratidão. Nesse sentido, a moral não tem nada a ver com essas questões. No entanto, a moral está, sim, relacionada às demissões perversas e ao tratamento desumano praticado por algumas organizações durante a demissão.

N uma sociedade que se diz cada vez mais democrática e transparente, é importante que as organizações e instituições que lhe dão corpo saibam que o social exerce sobre elas certo controle, e que Ihe será exigido um comportamento que respeite o ser humano individual e coletivo. A maior parte das organizações declara em voz alta que respeita a dignidade humana, e é bom para elas que isso seja verdadeiro. Mas quando elas dão provas de degradar em ações o que aplaudem em palavras, é preciso denunciá-las dentro de sua própria lógica. Fala-se muito em responsabilidade social, em condutas responsáveis, em virtudes organizacionais. No entanto, nunca na história das organizações se têm visto tantas denúncias de corrupção, escândalos, sabotagens, espionagens, mau comportamento organizacional, assédio moral, humilhações no trabalho e expressões de sadismo. ${ }^{5}$

Trata-se de um paradoxo: quanto mais se escreve sobre ética e responsabilidade, menos parece que ela é praticada. Em boa medida, percebemos que o que muitos chamam correntemente de ética é mais a preocupação com o comportamento desviante, que pode ser alvo do interesse da mídia e sujar-Ihes a reputação. Não existe moral nem ética de empresa. 0 que existe é ética de pessoas, e são elas que podem al terar o comportamento chamado organizacional. É claro que o comportamento não é um mero decalque do individual, mas uma gestão exercida por pessoas que valorizam um comportamento mais humano, mais responsável e mais honesto e saudável. Tal comportamento tenderá a produzir decisões em que os aspectos éticos serão considerados relevantes. Moral e ética são escoIhas que não negociam com circunstâncias. Infelizmente, não costumam ser critérios para a escolha de chefes.

Também acontece que, na ânsia por resultados rápidos, determinados perfis gerenciais parecem ser mais apropriados que outros. N essa decisão, em que a rapidez valida a escolha dos dirigentes, não raro se fecham os olhos à ausência de outros atributos que possam sacrificar resultados de longo prazo. Políticas predatórias de recursos humanos, desmandos e abusos de poder parecem ser legitimados em nome dos resultados rápidos.

As empresas não são apenas lugares de trabalho. São também espaços em que as pessoas desenvolvem laços fortes de amizade, constroem expectativas de futuro, aderem a um imaginário que Ihes fala de um projeto comum, ancoram uma parte de sua identidade social, enfim, um sistema que ultrapassa a sua finalidade econômica. A demissão é o ritual que degrada todas essas vinculações. Ela já é por si mesma uma essência cruel para quem está sendo desligado. Não existe nada, al ém de perversidade e sadismo, que justifique que um chefe ou uma empresa humi l he al guém quando o demite no final do expediente. Tomam-Ihe o crachá imediatamente, limpando seu nome de todos os 
computadores como se esse recente ex-colaborador fosse apenas um arquivo "deletável" na vida, impedindo-o de se despedir de seus colegas de longa data. Isso é uma forma de negação dessa pessoa como pessoa; é a negação da biografia desse sujeito, uma tentativa de apagar o seu passado e suas vinculações, tratando-o como uma coisa que não tem sentimentos nem humanidade. Tal comportamento, por parte de certas empresas, é abominável e deve ser objeto de todas as reprovações. Q uando isso ocorre, é a organização como um todo que se degrada aos olhos dos que ficam, envergonhando a todos os que dela fazem parte. Joga lama em todos os que se sen- tem tocados por essa indignidade, cuja impotência em dar uma resposta gera o silêncio com jeito de cumplicidade. Nenhum discurso pode apagar o estrago feito por ações como essas. 0 que fica é uma mágoa du radoura para quem foi e para quem ficou.

Costumo dizer que as organizações não são clubes, nem de anjos nem de suicidas. Contudo, sempre podemos encontrar uns anjos caídos por aí. Esses, além de maldosos, costumam também ser suicidas, e um perigo quando têm um pouquinho de poder nas mãos. Uma organização que não se abstém de alimentar seus anjos caídos, mais cedo ou tarde cairá junto com eles.

\section{NOTAS}

${ }^{1}$ Veja em FREITAS, M. E. O day-after das reestruturações: as irracionalidades e a coisificação do humano. RAE Light, v. 6, n. 1, p. 5-7, 1999.

2 Ibidem, p. 6.

${ }^{3}$ Veja em CALDAS, M. P. D emissões. São Paulo: Atlas, 2000.

4 Veja em COMTE-SPONVILLE, A. Le capitalisme est-il moral? Paris: Albin Michel, 2004. Há tradução para o português: 0 capitalismo é moral? São Paulo: Martins Fontes, 2005.

${ }^{5}$ Veja em FREITAS, M. E. Existe uma saúde moral nas organizações? Revista Organização e Sociedade (O\& S), n. 2, 2005.

\section{Artigo recebido em 21.07.2005. A provado em 17.11.2005.}

\section{Maria Ester de Freitas}

Professora titular da FGV-EAESP. Doutora em Administração de Empresas pela

FGV-EAESP com pós-doutorado em Administração Intercultural pela HEC-França.

Interesses de pesquisa nas áreas de teoria e análise das organizações, cultura e imaginário organizacional, recursos humanos e administração intercultural.

E-mail: mfreitas@fgvsp.br

Endereço: Av. 9 de Julho, 2029, Bela Vista, São Paulo - SP, 01313-902. 